\title{
Gerenciamento de resíduos na construção civil brasileira: uma abordagem teórica sobre reciclagem e logística reversa
}

\author{
Carolina Tavares Sancho Monteiro \\ Instituto Federal Fluminense (IFF) \\ (carolinasancho@id.uff.br)
}

\begin{abstract}
Resumo: A indústria da construção civil é responsável pela produção de até $70 \%$ do total dos resíduos sólidos urbanos (BRASIL, 2005). A geração desses resíduos no Brasil ocorre em quantidade tão significativa que se torna necessário escoá-los adequadamente para minimizar os impactos ambientais e econômicos das deposições ilegais na malha urbana e evitar o esgotamento de aterros. O setor possui um desafio: o de conciliar suas atividades produtivas com práticas sustentáveis. Em vigor desde 2015, a Resolução CONAMA 469 estabelece obrigações para os geradores de resíduos e para os municípios, fazendo com que os mesmos adaptem seus processos de modo a garantir a destinação correta dos mesmos. Os resíduos de construção e demolição apresentam uma grande variedade de oportunidades de geração de novos materiais, além de geração de emprego e economia para o construtor. No gerenciamento, o poder público deve exercer papel de agente gestor do sistema implantado, criando estruturas gerenciais adequadas e renovando os procedimentos de informação e de fiscalização (PINTO, 2001). Este trabalho tem como objetivo, através de uma revisão de literatura, abordar as diferentes cadeias logísticas relacionadas à gestão de resíduos de construção e demolição, bem como casos de sucesso implementados em diferentes localidades no Brasil.
\end{abstract}

Palavras-chave: resíduos de construção e demolição, reciclagem na construção civil, logística reversa na construção civil.

\section{Waste management in Brazilian construction: a theoretical approach of recycling and reverse} logistics

Abstract: The construction industry is responsible for the production of up to $70 \%$ of the total solid urban waste (BRASIL, 2005). The generation of this waste in Brazil is so big that it is necessary disposing it correctly in order to minimize the environmental and economic impacts of the illegal depositions in the city and to avoid the exhaustion of landfills. The sector has a challenge that is to reconcile its productive activities with sustainable practices. Operative since 2003, the CONAMA 369 Resolution establishes obligations for waste generators and for the city, forcing them to adapt their processes in order to guarantee their correct disposal. Construction and demolition waste present a wide variety of opportunities to generate new materials and products, as well as job creation and savings for the builder. In the management, the public power should play the role of managing agent of the implanted system, creating adequate management structures and renewing the information and inspection procedures (PINTO, 2001). This study intends to provide , through a literature review, the different logistic chains related to the management of construction and demolition waste, as well as success cases implemented in different locations in Brazil.

Keywords: construction and demolition waste, recycling in construction, reverse logistics in construction. 


\section{INTRODUÇÃO}

Sem uma boa gestão de resíduos sólidos, não se pode construir uma cidade sustentável e habitável. Não se tratam apenas de soluções técnicas; existem impactos climáticos, de saúde e segurança, bem como considerações sociais importantes, que dependem da mudança de comportamento para que as pessoas e as sociedades sejam encorajadas a reduzir e reciclar o lixo (ONU, 2016).

Objetivando a sustentabilidade, desenvolveu-se recentemente o conceito de urban mining (mineração urbana). O termo denota a reutilização de materiais de áreas urbanas, baseado no fato de que grandes estoques de materiais são incorporados nas cidades, particularmente em prédios e infraestruturas, mas também em áreas de aterro. Esses estoques representam um grande potencial de recurso que podem se tornar disponíveis para reuso (BRUNER, 2011), sendo na maioria das vezes fortemente baseado na viabilidade econômica. Entretanto, em algumas atuais estratégias, questões políticas e sociais podem se sobrepor a questões econômicas e levar à condução de práticas de reciclagem de materiais mesmo não havendo lucro no processo (COSSU et al., 2015).

Sendo considerada uma das atividades mais importantes para o desenvolvimento da sociedade, a construção civil é um dos principais setores na economia brasileira. No entanto, é uma grande causadora de impactos ambientais, uma vez que utiliza recursos naturais, modifica o meio ambiente e gera um grande volume de resíduos. Os resíduos de construção e demolição (RCD) são produzidos ao longo da vida útil de um projeto, envolvendo construção, uso/manutenção e demolição. Os mesmos podem ser provenientes de erros de projeto, falhas técnicas ou falta de gerenciamento no próprio canteiro de obras (ZORDAN, 1997). Esses representam estoques que apresentam uma grande variedade de oportunidades para a produção de agregados reciclados, novo concreto, tijolos de argila, cerâmica, etc.

Por serem decorrentes de diferentes materiais e processos construtivos, os RCD possuem uma constituição heterogênea e de várias dimensões, o que gera uma dúvida no construtor quanto à possibilidade de reciclagem do mesmo. Por esse motivo, as primeiras pesquisas científicas envolvendo o uso de agregados reciclados de RCD foram realizadas apenas em Pinto (1986), discutindo sua utilização em argamassa. Somente onze anos após, Zordan (1997) pesquisou sua utilização no concreto. 
Estima-se que metade do material gerado pelo setor da construção civil seja depositada irregularmente em meio urbano, ocasionando gastos na ordem de milhões para que as prefeituras municipais os destinem adequadamente (GUSMÃO, 2008). A forma de gerenciamento aplicada no Brasil e no exterior pelo poder público é a limpeza repetitiva de áreas de deposição ilegal dentro da malha urbana e posterior destinação a aterros municipais (PINTO, 1999; SCHNEIDER, 2003). Alguns efeitos são esperados desta deposição irregular: proliferação de insetos e roedores, assoreamento de córregos, entupimento de galerias, contaminação de águas subterrâneas, dente outros.

A busca por soluções que impliquem o aumento da produtividade e diminuição do desperdício na construção civil é de extrema importância no atual contexto de desenvolvimento urbano. A quantidade de RCD gerada em um município brasileiro pode variar de $54 \%$ a $70 \%$ do total dos resíduos sólidos urbanos (BUTTLER, 2007). Em diversos estudos, são apontadas como alternativas para a redução dos resíduos sólidos despejados em aterros ou em áreas não autorizadas pelas prefeituras, a logística reversa e a reciclagem em si (LEITE, 2001). O objetivo dessas alternativas é retornar com o material ao ciclo produtivo, readquirindo valor nos próprios mercados ou nos secundários.

Ainda são muitos os problemas existentes, sejam por falta de competência técnica, verba, desinteresse público ou efetivo planejamento para gestão dos RCD nos municípios (TESSARO et al., 2012). Por esses motivos, os mesmos permanecem na inércia de iniciar os planejamentos. Apesar do grande volume de estudos, poucas são as iniciativas públicas e privadas para adoção da prática, são pontuais as legislações e muitas das vezes não obedecidas, além de poucas ações de estímulo à reutilização dos resíduos e falhas na quantificação dos volumes que são gerados.

Em muitos países em desenvolvimento, a gestão de resíduos sólidos pode consumir de 20 a $50 \%$ do orçamento de uma cidade. Ressalta-se ainda que as operações são caras e que países em transição do status de baixa renda para renda média são particularmente atingidos, sem estrutura de imposto ou taxa para sustentar programas de resíduos sólidos e, o fator mais agravante, uma população acostumada a usar "gratuitamente" os lixões a céu aberto (ONU, 2016).

Diante desse cenário, foram observados inúmeros fatores que dificultam os municípios de seguir políticas de reutilização e redução dos impactos ambientais causados pelo setor Construção Civil. Nesse contexto, o estudo e posterior análise 
crítica da gestão ambiental dos resíduos da construção civil nas cidades brasileiras se tornou o tema central e objetivo dessa pesquisa.

\section{PROCEDIMENTOS METODOLÓGICOS}

O presente estudo se constitui em uma pesquisa exploratória, de natureza bibliográfica e documental, com abordagem qualitativa e descritiva. Para Zikmund (2000), os estudos exploratórios, geralmente, são úteis para diagnosticar situações, explorar alternativas ou descobrir novas ideias.

Sendo assim, este método foi adotado objetivando analisar e diagnosticar a situação atual dos resíduos gerados na construção civil brasileira perante a responsabilidade ambiental. Adotou-se o método dedutivo, fazendo a abordagem sobre a geração e utilização dos resíduos de construção e demolição no cenário internacional e, posteriormente o nacional.

A primeira etapa dessa pesquisa se baseou no mapeamento do estado da arte internacional, por meio do qual se objetivou obter o cenário da reciclagem de RCD nos mais variados países. Em seguida, buscou-se compreender a realidade brasileira. Foi observado o avanço quando comparada a literatura internacional à nacional $e$, sendo assim, foi necessária a consulta em periódicos e livros nacionais e internacionais, dissertações, teses e sites de instituições públicas nacionais.

Levando em consideração a incipiência do tema abordado, a pesquisa foi feita por meio de busca de palavras-chave nas seguintes bases de dados: Periódicos Capes, SciELO e Google Acadêmico, localizando assim os mais variados tipos de trabalhos que abordassem a temática, utilizando as seguintes expressões: legislação sobre resíduos construção civil, deposição de resíduos na construção civil, resíduos de construção e demolição, reciclagem na construção civil, logística reversa na construção civil, usinas de beneficiamento de construção civil.

Dessa forma, foi possível analisar a evolução da legislação quanto a obrigações do gerador de resíduos na construção civil e procurar estratégias sustentáveis utilizadas em cidades brasileiras com o objetivo de provar que além de necessário, é possível colocar a legislação em prática e destinar corretamente os resíduos obtidos na construção civil. 


\section{RESÍDUOS DE CONSTRUÇÃO E DEMOLIÇÃO}

Segundo a Resolução 469 do CONAMA (2015), os resíduos de construção civil são:

Os provenientes de construções, reformas, reparos e demolições de obras de construção civil, e os resultantes da preparação e da escavação de terrenos, tais como: tijolos, blocos cerâmicos, concreto em geral, solos, rochas, metais, resinas, colas, tintas, madeiras e compensados, forros, argamassa, gesso, telhas, pavimento asfáltico, vidros, plásticos, tubulações, fiação elétrica etc., comumente chamados de entulhos de obras, caliças ou metralha (CONAMA, 2015).

Além de estabelecer diretrizes, critérios e procedimentos para a gestão dos resíduos da construção civil, essa resolução faz uma série de definições dos termos técnicos e sinaliza que geradores devem ter como objetivo prioritário a não geração de resíduos, e, secundariamente, a redução, reutilização, reciclagem, tratamento dos resíduos sólidos e disposição final ambientalmente adequada dos rejeitos (CONAMA, 2015).

De forma a possibilitar e facilitar o reuso, a resolução faz a seguinte classificação:

a) Classe A - São resíduos reutilizáveis ou recicláveis como agregados, tais como de construção, demolição, reformas e reparos de pavimentação sejam eles componentes cerâmicos, argamassa ou concreto;

b) Classe B - São os resíduos recicláveis para outras destinações, tais como plástico, papel, papelão, metais, vidros, madeiras, embalagens vazias de tintas imobiliárias e gesso;

c) Classe C - São resíduos para os quais a reciclagem não é economicamente viável ou não existe tecnologia desenvolvida para a mesma;

d) Classe D - São resíduos perigosos tais como amianto, tintas, óleos e outros contaminados prejudiciais à saúde.

A composição dos resíduos de construção e demolição é variável, dependendo da indústria local, qualidade da mão de obra envolvida, técnicas construtivas utilizadas, procedimento de gerenciamento, da adoção de programas de qualidade, da fase da obra, etc. Segundo (BAPTISTA et al., 2013), na Bélgica, os resíduos de concreto e alvenaria são responsáveis por $83 \%$ do total, enquanto a madeira contribui 
com apenas 2\%; em Toronto, cerca de 35\% provêm da utilização de madeira. No Brasil, assim como na Bélgica, é alto o volume de resíduos de argamassa e concreto, chegando até a 72\% enquanto a madeira fica em torno de 1\% (SILVA, 2005 apud SANTOS, 2009).

Segundo a ABRELPE (2016), o dado da geração de RCD no Brasil para o ano de 2016 foi de 45,1 milhões de toneladas de RCD, sendo $123.619 \mathrm{t} /$ dia ou 0,600 $\mathrm{kg} / \mathrm{hab} / \mathrm{dia}$, enquanto em 2014, em países europeus como Alemanha esse valor foi de $0,007 \mathrm{~kg} / \mathrm{hab} / \mathrm{dia}$ e Holanda 0,015 kg/hab/dia (EUROSTAT, 2014). Apesar da quantidade de resíduo de construção e demolição perante a todos os resíduos produzidos apresentar valores altos para esses países (53\% e 74,5\%), observa-se que ainda é muito menor que os índices brasileiros.

Dentre os inúmeros fatores que contribuem para a geração dos RCD no Brasil, estão os problemas relacionados ao projeto, seja por falta de definições e detalhamentos, precisão no memorial descritivo, baixa qualidade dos materiais ou falta de qualificação da mão de obra, manejo, transporte ou armazenamento inadequado dos materiais, o tipo de técnica escolhida para construção ou demolição e finalmente, a falta de processos de reutilização e reciclagem no canteiro.

Pinto (1999) indica que $25 \%$ dos materiais que entram nos canteiros de obras são descartados. Sua pesquisa deixa clara a falta de cuidados que as empresas de construção têm com a utilização correta dos insumos. Em uma pesquisa na cidade de João Pessoa, 60\% das construtoras entrevistadas disseram desconhecer a obrigação legal do projeto de gestão e o conteúdo da até então Resolução 307/2002, hoje alterada para 469/2015 do Conama (FERNANDES et al., 2010).

Nos Estados Unidos e em alguns países da Europa, a reciclagem de resíduos da construção para produção de agregados é realidade há mais de trinta anos (PHILIPPI et al., 2004). Os mesmos autores citam que a Holanda recicla $70 \%$ de seus entulhos, a Alemanha, 30\% e a cidade de Copenhague, capital da Dinamarca, cerca de $25 \%$. Nesses países, existe uma política ambiental austera e leis rigorosas que punem a deposição irregular de resíduos e premiam iniciativas que visam o reaproveitamento e reciclagem. O aspecto cultural é muito relevante para a existência deste quadro, além dos altos custos para destinação de resíduos e baixa oferta de recursos naturais para matéria-prima.

De acordo com a OECD (Organization for Economic Co-Operation and Development), citado por Corrêa et al. (2009) em países como a Bélgica, Dinamarca, 
Japão e Holanda, a sociedade exerce uma grande pressão contra a utilização de áreas para a deposição de resíduos e a exploração desenfreada de recursos naturais; por esse motivo, o reaproveitamento e a reciclagem de resíduos ocupam um local de destaque na agenda política desses países. No Reino Unido, por exemplo, a cobrança de taxas sobre a deposição de resíduos de concreto incentivou as usinas de concreto pré-misturado a diminuir substancialmente a quantidade de resíduos gerados (PHILIPPI et al., 2004).

No Brasil, estima-se que em média $65 \%$ do material descartado é de origem mineral, $13 \%$ madeira, $8 \%$ plásticos e $14 \%$ de outros materiais. As construtoras são responsáveis pela geração de 20 a $25 \%$ desse entulho, sendo que o restante provém de reformas e de obras de autoconstrução, conforme Techne (2001) citado por Vieira (2003). As deposições ilegais de RCD normalmente ocorrem em função de custo com transportes. Embora existam leis que proíbam tal atividade, as mesmas só se tornam efetiva quando também é interessante economicamente. Para isso, é necessária a inserção de pontos de coleta estrategicamente posicionados dentro da malha urbana, para minimização de custos com transporte (PINTO, 1999).

Para Terry (2004) citado por Cabral (2010), a legislação é o maior fator que afeta o gerenciamento de resíduos na indústria da construção civil brasileira. Sem uma legislação efetiva em vigor e principalmente uma forte fiscalização, não é possível alcançar o sucesso no gerenciamento de resíduos. Através de políticas governamentais de incentivo ao reuso e valorização do resíduo, pode existir futuro para a reciclagem na construção civil. Com uma maior aceitação do produto e possivelmente a futura indisponibilidade de aterros, o mesmo deve ser inserido como matéria-prima e não como rejeito na linha de produção. A legislação, por sua vez, vem evoluindo no que se diz respeito à gerenciamento e reutilização dos RCD nas escalas nacionais, estaduais e municipais, exigindo inúmeros deveres tanto dos geradores quanto dos agentes públicos envolvidos no processo.

Ainda nesse contexto, vale ressaltar a importância da educação ambiental em todas essas esferas, pois, para muitos brasileiros, é uma abordagem ainda nova e pouco explorada, sendo assim, muitas vezes, não reconhecida como necessidade. Por questões que perpassam o desenvolvimento histórico do Brasil e cultura, nota-se uma inércia em se reproduzir o solicitado pela legislação, tanto para o gerador de resíduos, quanto para o órgão público, que não age com fiscalização efetiva e punições severas. 


\section{RECICLAGEM E LOGÍSTICA REVERSA}

A indústria da construção sofre com a fragmentação ao longo das fases do ciclo de vida do empreendimento. Normalmente são envolvidos muitos agentes no desenvolvimento de projetos, tais como empreendedor, projetistas, consultores, subcontratados, fornecedores, dentre outros. Esse comportamento se dá devido à organização ser feita em etapas isoladas, onde projeto e execução têm responsabilidades, metas e objetivos diferentes (MITCHELL et al., 2011).

Muitos países investem em um sistema formal de gerenciamento de resíduos de construção e demolição, e quase todas as políticas incluem a reciclagem dos mesmos. No Brasil, geralmente o sistema é composto por companhia para transporte, pontos de coleta para pequenos e grandes geradores e aterros, incluindo ou não as usinas de beneficiamento do resíduo (PINTO, 1999).

Desde 2002, o gerenciamento desses resíduos está previsto na resolução no 307 do Conselho Nacional do Meio Ambiente (CONAMA), direcionando ao município a definição de uma política municipal para RCD, priorizando a reciclagem da geração de origem mineral, que representa $90 \%$ da massa desse resíduo. Economicamente, a reciclagem de RCD será atrativa quando os produtos reciclados tiverem custo menores e qualidade comparáveis aos naturais. Sendo assim, os materiais reciclados serão mais competitivos em regiões onde houver escassez de materiais naturais e áreas para aterros (TAM et al., 2006).

Muitos autores apontam esse fato quando se discute a evolução da reciclagem de RCD num panorama mundial. Alguns países europeus e o Japão, por exemplo, possuem políticas mais elaboradas e consolidadas, podendo este fato ser justificado em razão da carência de espaço físico para criação de aterros e densidade demográfica. A difusão da reciclagem de resíduos da construção civil começou na Alemanha após a Segunda Guerra Mundial e posteriormente nos demais países da Europa (PINTO, 1999). Provavelmente por essa prática ter se iniciado há muitos anos, são lugares que apresentam normas e políticas para reciclagem completamente avançadas.

Normalmente a reciclagem de RCD se resume à produção de agregados reciclados, que é, de forma simplificada, um beneficiamento mineral. Dentre as operações feitas nas usinas, usualmente é empregada a britagem e peneiramento dos 
resíduos, podendo ser repetida diversas vezes a fim de se reduzir as partículas a tamanhos desejados.

As primeiras usinas instaladas no Brasil foram feitas em São Paulo em 1991. Em 2009, havia cerca de 48 usinas instaladas no país, sendo que metade eram públicas. Nesse mesmo ano, a reciclagem de RCD era estimada em 4,8\% e havia uma previsão de crescimento no mercado de usinas móveis (MIRANDA et al., 2009).

Por meio da resolução CONAMA 307, da Política Nacional de Resíduos Sólidos, da Lei № 12.305 de agosto de 2010 e da última regulamentação por meio do decreto no 7404 de dezembro de 2010, um novo marco no setor de resíduos de construção foi promovido, dando força à gestão e reciclagem de RCD (ABRECON, 2015). Conforme os dados levantados pela ABRECON (2015) conforme mostrado no Gráfico 1, até 2002 havia um índice de crescimento de 3 novas usinas por ano, totalizando 16 usinas instaladas no país ao final deste ano. Após a resolução CONAMA 307, essa taxa chegou a 9 usinas por ano até o ano de 2007. De 2008 a 2013 observou-se um aumento de até 10,6 usinas por ano, mas de 2013 a 2015 observou-se uma estabilidade nessa quantidade de usinas.

Segundo os dados de Miranda et al. (2009), até 2002 a maior parte das usinas era do setor público, porém, após esse ano esse quadro mudou. Em 2008 cerca de metade das usinas pertenciam à iniciativa privada. Com base nas 105 usinas que responderam à pesquisa, $83 \%$ pertenciam à iniciativa privada, 10\% à gestão pública e 7\% público-privada. De acordo com o mesmo autor, o aumento de usinas privadas decorre da perspectiva dos empresários de essa ser uma boa alternativa de investimento, com baixo capital inicial e alta taxa de retorno. 
Gráfico 1: Levantamento de usinas de reciclagem de RCD no país ao longo dos anos

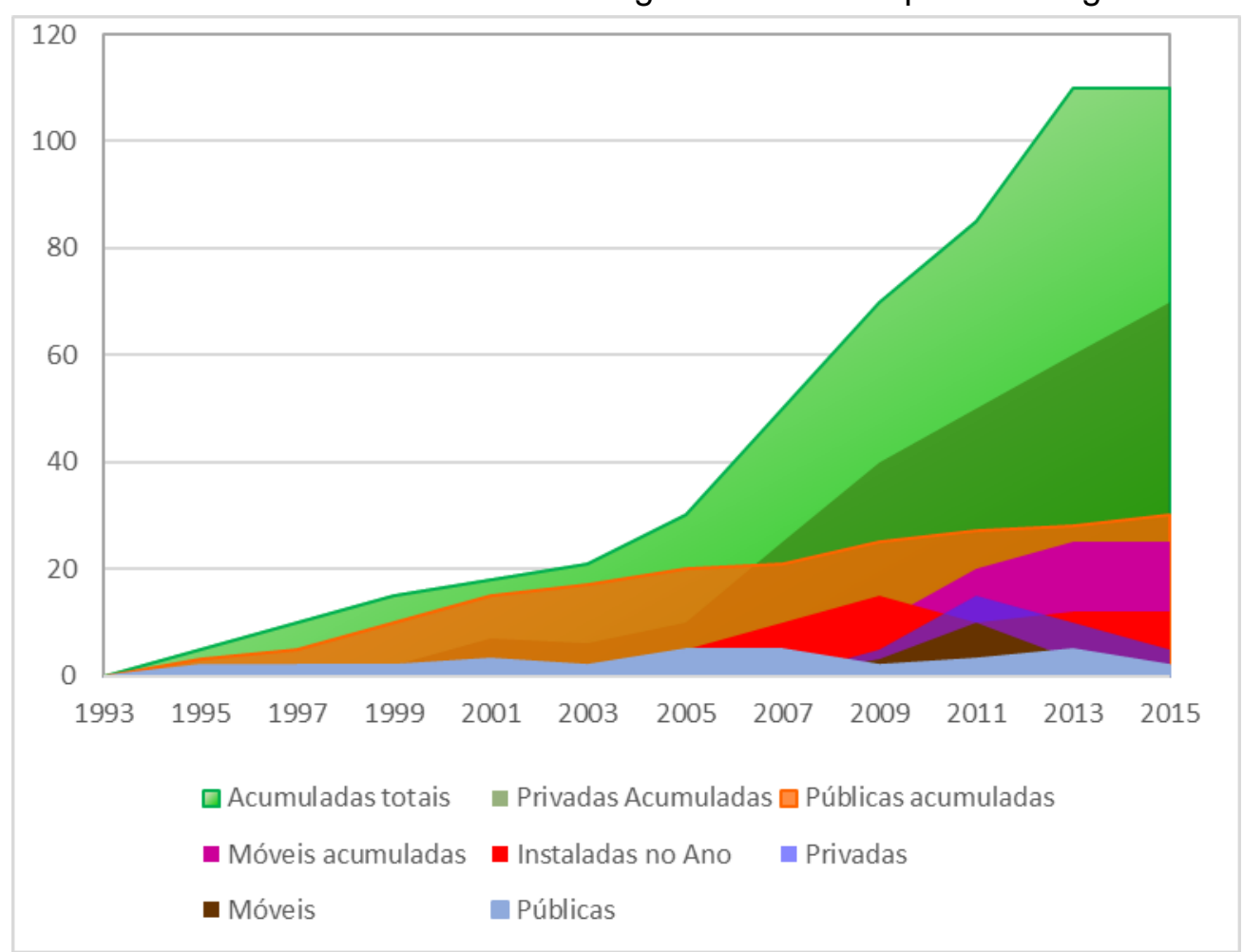

Fonte: Adaptado de ABRECON (2015)

$\mathrm{Na}$ Bélgica, os resíduos são transformados em agregados reciclados e reutilizados nos serviços de pavimentação pública, com uma economia de até $45 \%$ nos custos dos projetos, sendo que $70 \%$ dessa economia está relacionado a diminuição dos custos de transportes, $20 \%$ da aquisição do material de menor valor e $10 \%$ do não pagamento das taxas para despejo de resíduos em aterros (HANSEN, 1992 apud CABRAL, 2007).

No Reino Unido, o balanço financeiro aponta que o custo para transformação dos resíduos em agregados reciclados está se tornando mais barato que o custo da deposição desses resíduos e compra de novos agregados. Isso se deve ao aumento de taxas para deposição dos resíduos em aterros e à introdução de impostos sobre os agregados (DHIR et al., 2004).

No Brasil, a questão do gerenciamento de resíduos está completamente relacionada ao problema de desperdício de materiais e mão de obra na execução de um empreendimento. Para que uma efetiva gestão seja conduzida, boas práticas no canteiro são de extrema importância para a redução de resíduos produzidos na obra. O correto manejo permite a identificação de materiais reutilizáveis, que geram 
economia tanto por dispensarem a compra de novos materiais como por evitar sua identificação como resíduo e gerar custo de remoção (D’ALMEIDA et al., 2000).

Nesse contexto, a implantação da logística reversa revela-se como uma grande oportunidade de desenvolver a sistematização dos fluxos de resíduos, seja pelo fim de sua vida útil ou por outro motivo, possibilitando seu reaproveitamento dentro ou fora da cadeia produtiva que o originou, contribuindo para a redução do uso de recursos naturais. O sistema logístico reverso consiste em uma ferramenta organizacional com o intuito de viabilizar técnica e economicamente as cadeias reversas, de forma a contribuir para a promoção de sustentabilidade da cadeia produtiva, ampliando o ciclo de vida útil ou, após extinta sua vida útil, retornando ao ciclo produtivo e readquirindo valor em mercados secundários.

Este conceito é relativamente novo e em evolução. Embora esta área esteja sendo explorada pela indústria seriada desde 1975 em países desenvolvidos, como Inglaterra e EUA (CARTER et al., 1998), somente recentemente, na última década, começou a ser estudada no Brasil. Baptista (2013) estudou uma forma viável para tratar os resíduos da construção civil por logística reversa na cidade do Rio de Janeiro. O autor propõe que o atual processo industrial linear (Figura 1), seja substituído por uma logística circular, de natureza sustentável, onde os resíduos possam voltar a ser incorporados à produção (Figura 2).

Figura 1: Processo linear de descarte

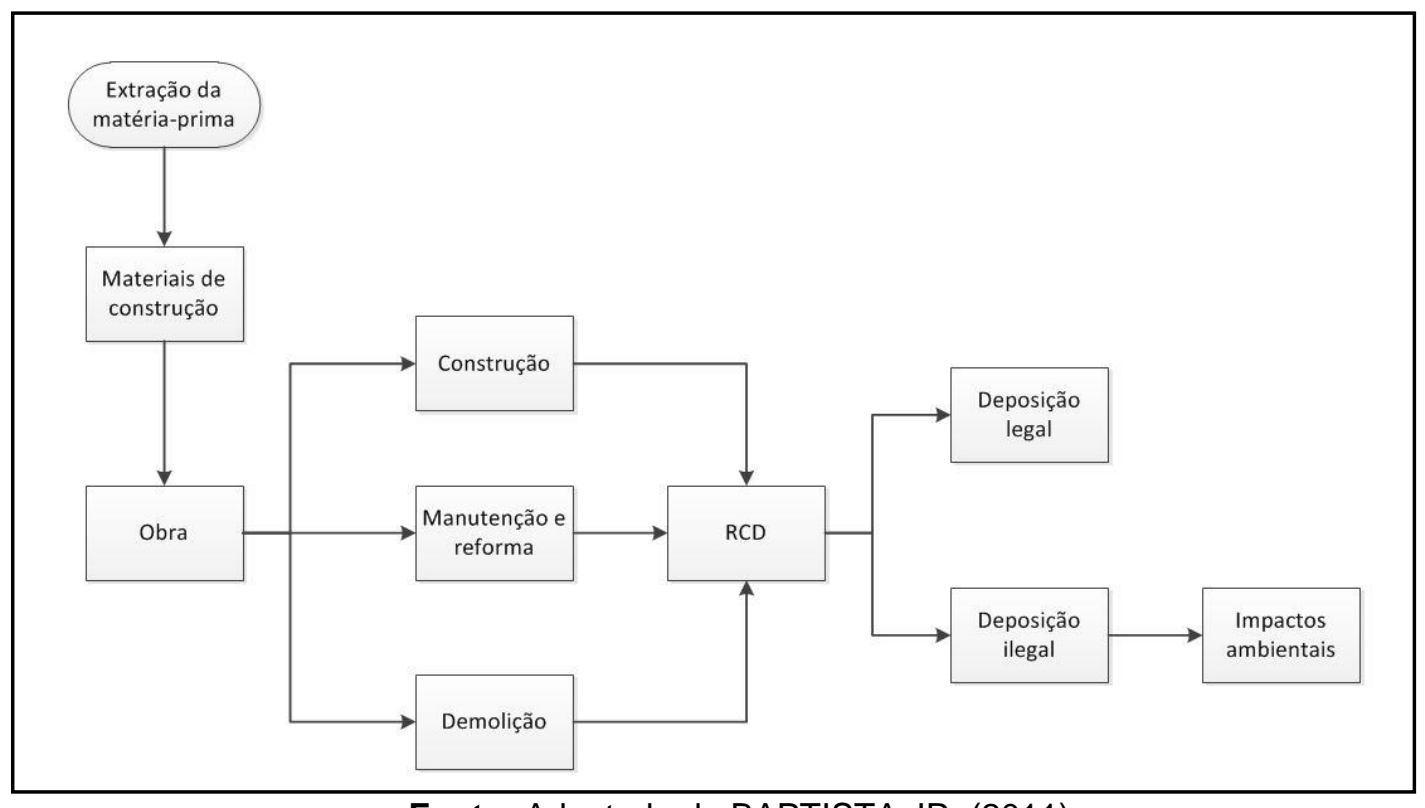

Fonte: Adaptado de BAPTISTA JR. (2011). 
Segundo o autor, para implantação dessa logística reversa é necessário que o processo de reciclagem inicie na própria obra, com a segregação dos produtos de acordo com suas classes. Os bairros teriam pontos estrategicamente localizados (ecopontos) que serviriam como uma opção de armazenamento seletivo, recebendo resíduos de pequenas obras. Essa técnica de armazenamento em ecopontos teria a função de atender os pequenos construtores espalhados pela cidade, e garantir a existência de quantidades economicamente viáveis para transporte dos resíduos ao centro de tratamento.

As obras maiores, por sua vez, deveriam depositar direto na central de tratamento, uma vez que, segundo a Resolução 387, as grandes obras (áreas maiores que $10.000 \mathrm{~m}^{2}$ ) são obrigadas a segregar o próprio entulho. Sendo assim, os resíduos classe A recebidos na central de tratamento, passariam pelo processo de beneficiamento e voltariam para a cadeia de produção como matéria prima. Os resíduos classe $B$, seriam encaminhados para centros de reciclagem de outros mercados como plástico, vidro, dentre outros. Os resíduos de classes C e D, por sua vez, seriam depositados em locais apropriados, uma vez que para o $C$ atualmente não existe tecnologia para reciclagem e o resíduo $D$ é perigoso, devendo ser corretamente destinado.

Figura 2: Processo circular de reciclagem e disposição final de resíduos de construção e demolição.

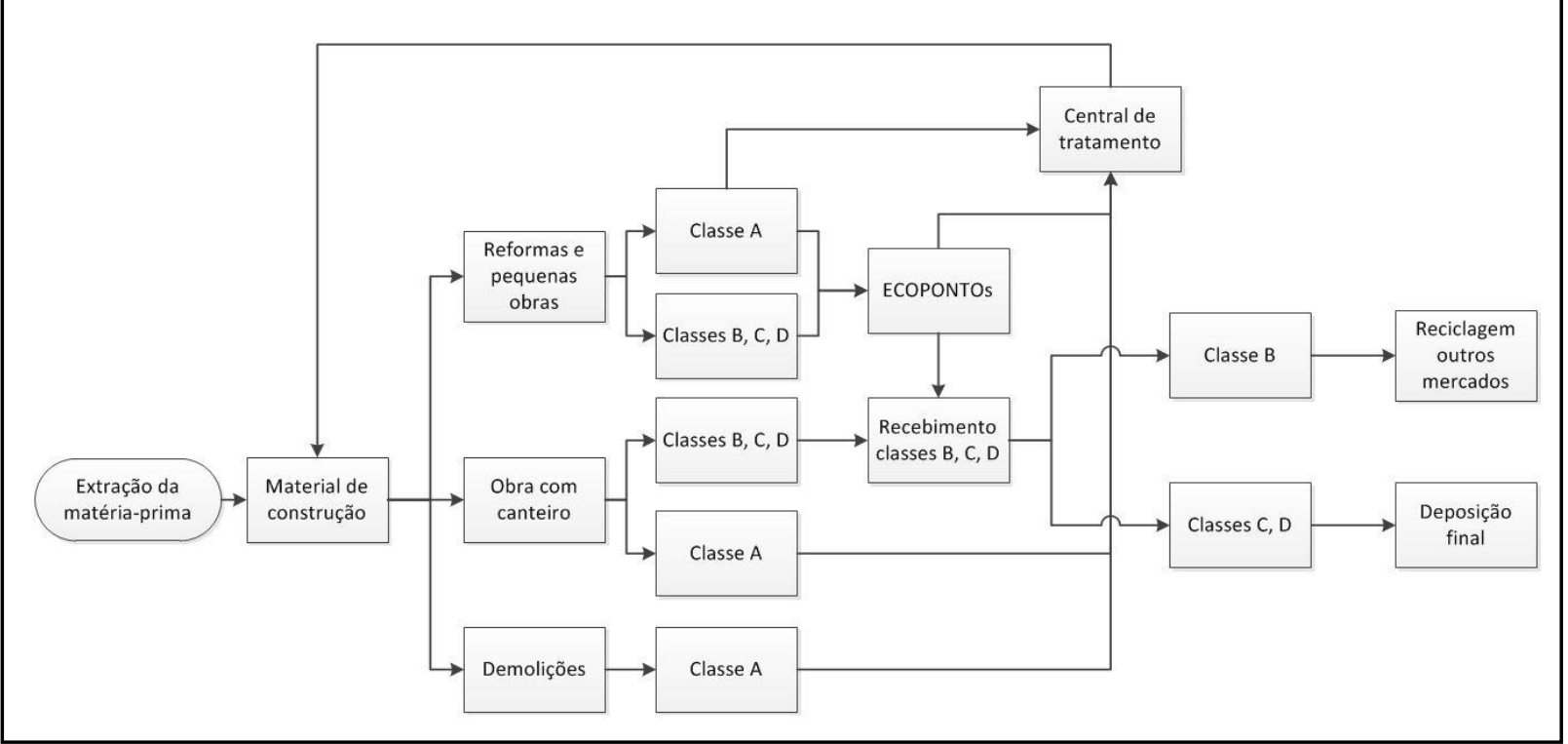

Fonte: Adaptado de BAPTISTA JR. (2011). 
As condições necessárias para o sucesso da implantação dessa logística são: existência de regulamentação colocada em prática pelo poder público, infraestrutura necessária para o processo e conscientização dos geradores e da sociedade em geral.

Gonçalves (2016), em seu trabalho, retrata a gestão de resíduos em Uberaba, separando os geradores em dois grupos: os que geram abaixo e acima de $1,0 \mathrm{~m}^{3} \mathrm{de}$ resíduo. O grande gerador, por sua vez, deveria elaborar seu Plano de Gerenciamento de Resíduos Sólidos e providenciar coleta e destinação correta. Já ao pequeno gerador era oferecido o serviço de coleta pública, estabelecida em ecopontos estrategicamente localizados pela cidade.

O sistema de gestão do Município de Sorocaba e sua implementação foi considerada um sucesso, porém, pontuou-se a relevância de envolvimento de ações de educação ambiental para a população e a importância da fiscalização para o alcance de melhores resultados.

Além de diminuir os resíduos despejados em locais impróprios e em aterros, a iniciativa da prefeitura de criação de uma usina de beneficiamento gerou empregos através de parceria com a cooperativa de trabalhadores e economia para os cofres públicos, uma vez que os resíduos beneficiados eram utilizados em obras públicas (GONÇALVES, 2016).

Evangelista et al. (2010) realizaram uma pesquisa em Salvador, Bahia, onde foram feitos estudos de caso visando entender o processo de logística reversa dentro do canteiro, bem como desenvolver uma primeira proposta sistemática de identificação do melhor fluxo de atividades. Foram escolhidos três tipos de obras de médio e grande porte em diferentes fases (alvenaria e revestimento; estrutura e revestimento; estrutura e alvenaria).

Em suas conclusões, os autores pontuaram que a possibilidade de reciclagem dos resíduos classe A no próprio canteiro mostrou-se como uma excelente alternativa para destinação responsável dos resíduos de obra. Os agregados reciclados foram utilizados para regularização de vias de acesso e construção de pilaretes da área de convivência.

Segundo Fernandes et al. (2010), na sua coleta de dados ficou evidenciada a forte influência do fator cultural, posto que as construtoras brasileiras entrevistadas avaliaram mudanças em rotinas laborais como algo extremamente desgastante, que 
requer tempo e muitas vezes não tem êxito, sendo classificado por $70 \%$ dos funcionários como aborrecimento, perda de tempo e dinheiro.

Apesar de iniciativas públicas de algumas cidades do Brasil, ainda é muito pequena a quantidade de empresas da construção civil que realiza a gestão eficiente dos resíduos em seus canteiros. É ainda menor a prática do reaproveitamento e reciclagem. A segregação, acondicionamento e disposição final qualificada dos resíduos ainda não são realizados de forma adequada e integrada às atividades produtivas dos canteiros, conforme solicita a legislação (EVANGELISTA et al., 2010).

\section{CONSIDERAÇÕES FINAIS}

Não é possível que uma sociedade atinja o desenvolvimento sustentável sem que a construção civil, que lhe dá suporte, passe por profundas transformações (JOHN, 2001). Nas últimas duas décadas, o estudo da utilização dos resíduos de construção e demolição teve grandes avanços, principalmente com 0 desenvolvimento de novas leis e normas, possibilitando assim um fechamento do ciclo de vida dos materiais utilizados na construção civil.

A situação de geração de RCD no Brasil é alarmante. Com o forte crescimento das cidades e realizações de obras de infraestrutura, observa-se cada vez mais a destinação inadequada, inexistência de áreas de transbordo, esgotamento de áreas de destinação inadequada e inércia do poder público diante da situação. Isso posto, é reforçada a necessidade de um movimento em conjunto com toda a sociedade, no sentido de propor alternativas sustentáveis para minimizar seus impactos ambientais e promover sua destinação responsável. O aumento de usinas de beneficiamento de resíduos mostra uma evolução para o gerenciamento de $\mathrm{RCD}$, porém, ainda é grande a diferença entre a quantidade de usinas públicas e privadas. É preciso que o setor público estabeleça o gerenciamento de RCD conforme definido pela CONAMA 469 e aumente o número de usinas.

A eliminação do descarte de resíduos de construção civil em aterros sanitários e logradouros públicos deve ser vista como uma realidade possível de ser alcançada em um futuro próximo. Sendo assim, novas abordagens e técnicas devem ser elaboradas e colocadas em prática, como a proposta da logística reversa. Dessa forma, a atual situação de produção através de um processo linear onde o resíduo 
muitas vezes sai da obra visto como rejeito deve dar lugar à um processo cíclico, possibilitando uma logística circular de natureza sustentável, onde os resíduos são vistos como potencial fonte de novos materiais.

Apesar de existirem legislações que obriguem o gerador de resíduos a destinar corretamente o material a ser deposto, a realidade na maioria das cidades é o despejo de resíduos em logradouros públicos ou áreas particulares, onde o gerador omite-se da devida responsabilidade. Sendo assim, é de extrema importância efetividade da fiscalização para que a legislação seja colocada em prática, obrigando assim os geradores a destinarem corretamente os resíduos, possibilitando a logística reversa ou destinando os rejeitos corretamente.

Através das informações levantadas neste trabalho, podemos perceber 0 quanto é crítica a questão do destino dos resíduos de construção e demolição no Brasil. Em função do país ter uma grande extensão territorial e inúmeras reservas de recursos minerais, os geradores de resíduos não percebem ou priorizam a necessidade em reciclar os resíduos da obra. A população, por sua vez, não exige que isso seja feito, uma vez que as áreas de deposição ilegais ou legais são, na maioria das vezes, afastadas dos centros urbanos. Para que exista essa conscientização, será necessário investimento público para valorização da educação ambiental, promovendo uma mudança de hábitos culturais.

Constatou-se que em vários países, principalmente os da Europa, a prática da reciclagem do RCD é comum. Como citado anteriormente, essa é uma atividade em vigor desde o final da Segunda Guerra Mundial, quando houve a necessidade de uma massificação de reconstrução dos países, utilizando os recursos disponíveis no pósguerra, ou seja, os escombros das demolições. Dessa maneira, desde então, seja por limite de áreas ou não, através de métodos como a educação ambiental e práticas detalhadas e rigorosas das legislações vigentes, a sociedade como um todo consegue valoriza o resíduo, pois essa questão é abordada culturalmente e politicamente há sete décadas.

Com todas as informações apresentadas, esse estudo mostrou a incipiência do Brasil na questão da reciclagem de RCD. Em contrapartida, apresentou-se o sucesso da logística reversa em algumas cidades brasileiras. Foi discutida a necessidade da fiscalização e punição, além da criação de legislações, e a importância da participação de todos os agentes envolvidos no processo: poder público, empresas, engenheiros, arquitetos, alunos, professores e sociedade em geral em ações de educação 
ambiental para a população, objetivando alertá-la o valor que um resíduo previamente visto com rejeito pode ter. É preciso solidificar esse conceito na cultura da população brasileira em prol de um bem comum: a sustentabilidade das cidades.

\section{REFERÊNCIAS}

Associação Brasileira Para Reciclagem De Resíduos Da Construção Civil e Demolição (ABRECON). Relatório Pesquisa Setorial 2014/2015. Presidente: Hewerton Bartoli. Autor e elaboração: UFPR - Universidade Federal do Paraná, 2015.

Associação Brasileira De Empresas De Limpeza Pública E Resíduos Especiais (ABRELPE). 2016. Panorama dos resíduos sólidos no Brasil. p. 103. Disponível em: <http://www.abrelpe.org.br/ Panorama/panorama2016.pdf>. Acesso em: 15 de Junho de 2017.

Baptista Junior, J. V. \& Romanel, C. Sustentabilidade na indústria da construção: uma logística para reciclagem dos resíduos de pequenas obras. URBE - Revista Brasileira de Gestão Urbana, v. 5, n. 480, p. 27, 2013.

BRASIL. Ministério das Cidades. Ministério do Meio Ambiente. Áreas de manejo de resíduos da construção civil e resíduos volumosos: orientações para o seu licenciamento e aplicação da Resolução Conama 307/2002. Brasília, 2005.

Brunner, P.H. Urban Mining A Contribution to Reindustrializing the City. Journal of Industrial Ecology 15, 2011.

Buttler, A. M. Uso de agregados reciclados de concreto em blocos de alvenaria estrutural. 2007. 499 f. Tese (Doutorado em Engenharia de Estruturas) -- Escola de Engenharia de São 15 a 17 junho de 2016 Porto Alegre, RS Carlos, Departamento de Engenharia de Estruturas, Universidade de São Paulo - USP, São Carlos, SP, 2007.

Cabral, A.E.B. Modelagem de propriedades mecânicas e de durabilidade de concretos produzidos com agregados reciclados, considerando-se a variabilidade da composição do RCD. 280p. Tese (Doutorado). Escola de Engenharia de São Carlos, Universidade de São Paulo, 2007.

Cabral, A. E. B.; Schalch, V.; Dal Molin, D. C. C. \& Ribeiro, J. L. D. Mechanical properties modeling of recycled aggregate concrete. Construction and Building Materials, Vol. 24, p. 421-430, 2010.

Carter, C.R.; Ellram, L. M., Reverse logistics: a review of the literature and framework for future investigation. Journal of Business Logistics, vol.19, n.01, 1998.

Conselho Nacional Do Meio Ambiente (CONAMA). Resolução no 307. Brasília, 2002.

Conselho Nacional Do Meio Ambiente (CONAMA). Resolução no 469. Brasília, 2015. Altera 0 art. 3 da Resolução CONAMA 307/2002. 
Corrêa, M. R. S.; Buttler, A. M. \& Ramalho, M. A. Reciclagem de Materiais de Construção. Techne, PINI. 2009. Disponível em:<http://techne.pini.com.br/engenhariacivil/152/artigo286651-2.aspx/>. Acesso em: 02 de junho de 2017.

Cossu, R.; Williams, I.D. - Urban Mining: Concepts, terminology, challenges - Elsevier, p.1-3, 2015.

D’Almeida, M. L. O. \& Vilhena, A. Lixo municipal (Manual de gerenciamento integrado). São Paulo, IPT/CEMPRE, 2000.

Dhir, R.; Paine, K \& Dyer, T. Recycling construction and demolition wastes in concrete. Concrete, March, p. 25-28, 2004.

Evangelista, P. P. A.; Bastos Costa, D. \& Zanta, V. M. Sustainable alternative for the disposal of Class A construction residues: a process for recycling in building sites. Ambiente Construído, v. 10, n. 3, p. 23-40, set. 2010.

EUROSTAT (2014). European Commission. Waste Statistics Disponível em: <http://ec.europa.eu/eurostat/statistics-explained/index.php?title=Waste_statistics> Acesso em: 26 de Janeiro de 2018.

Fernandes, M. P. M \& Filho, L. C. P. S. Gestão de resíduos: Construção e desconstrução de conceitos no canteiro de obras. ENTAC 2010. XIII Encontro Nacional de Tecnologia do Ambiente Construído. 2010.

Gonçalves, D. B. A Gestão De Resíduos Da Construção Civil No Município De SorocabaSP. REEC - Revista Eletrônica de Engenharia Civil, v. 11, n. 2, 22 mar. 2016.

Gusmão, A. D. Manual de Gestão dos Resíduos da Construção Civil. Recife: Gráfica Editora, 2008.

John, V. M. Aproveitamento de resíduos sólidos como materiais de construção. In: Reciclagem de entulho para a produção de materiais de construção / Organizado por Alez Pires Carneiro, Irineu Antônio Schaldach de Brum e José Clodoaldo da Silva Cassa. Salvador. EDUFBA; 312p.; 2001.

Leite, M. B. Avaliação de Propriedades Mecânicas de Concretos Produzidos com Agregados Reciclados de Resíduos de Construção e Demolição. 2001. 270 f. Tese (Doutorado em Engenharia Civil) - Escola de Engenharia, Universidade Federal do Rio Grande do Sul, Porto Alegre, 2001.

Miranda, L.F.R., Ângulo, S. C. \& Careli, E. D. A Reciclagem de Resíduos de Construção e Demolição no Brasil: 1986 - 2008. Revista Ambiente Construído. Porto Alegre. V.9, n.1, 2009.

Mitchell, Adrian, Frame, lan, Coday, Alan \& Hoxley, Mike. A Conceptual Framework of the Interface Between the Design and Construction Processes. Engineering Construction and Architectural Management, v.18, n.3, p.297-311, 2011.

Organização Das Nações Unidas (ONU). Priorização de Gestão de Resíduos Sólidos nas Cidades Aumenta, diz Banco Mundial. Estados Unidos, 2016. Disponível em: <http://www.onu.org.br/>. Acesso em: 14 de junho de 2017.

Philippi JR, A., Romério \& M. A, Bruna, G. C. Curso de Gestão Ambiental. São Paulo: Manole, 2004. 
Pinto, T. P. Utilização de resíduos de construção. Estudo do uso em argamassas. São Carlos - SP. 137p. Dissertação (Mestrado) - Escola de Engenharia de São Carlos, Universidade de São Paulo, 1986.

Pinto, T. P. Metodologia para gestão diferenciada de resíduos sólidos da construção urbana. São Paulo-SP. 189 p. Tese (Doutorado) Escola Politécnica da Universidade de São Paulo, 1999.

Pinto, T. P. Gestão dos resíduos de construção e demolição em áreas urbanas. In: PROJETO ENTULHO BOM. Reciclagem de entulho para produção de materiais de construção. A. P. Carneiro, I. A. S. Brum, J; C. S. Cassa (Eds). Salvador: EDUFBA; Caixa Econômica Federal, 2001.

Santos, A. L. Diagnóstico ambiental da gestão e destinação dos resíduos de construção e demolição (RCC): análise das construtoras associadas ao Sinduscon/RN e empresas coletoras atuantes no município de Parnamirim - RN. 2009. 107 f. Dissertação (Mestrado) - Universidade Federal do Rio Grande do Norte, Natal, 2009.

Schneider, D. M. Transporte de resíduos de construção e demolição na cidade de São Paulo. 2003. 103p. Dissertação (Mestrado) - Faculdade de Saúde Pública, Universidade de São Paulo. São Paulo, 2003.

Tam, V. W. Y. \& Tam, C. M. A review on the viable technlogy for construction waste recycling. Resources, Conservationd and Recycling. Vol. 47, p. 209-221, 2006.

Tessaro, A. B., Sá, J. S. \& Scremin, L. B.. Quantificação e Classificação dos Resíduos Procedentes da Construção Civil e Demolição no Município de Pelotas, RS. Ambiente Construído, Porto Alegre, v. 12, n. 2, p. 121-130, abr./jun. 2012.

Vieira, G. L. Estudo do processo de corrosão sob a ação de íons cloreto em concretos obtidos a partir de agregados reciclados de resíduos de construção e demolição. Porto Alegre-RS. 151p. Dissertação (Mestrado). Programa de Pós-Graduação em Engenharia Civil da Universidade Federal do Rio Grande do Sul, 2003.

Zordan, S. E. A Utilização do Entulho Como Agregado, na Confecção de Concreto. Campinas, 1997. 156 f. Dissertação (Mestrado em Engenharia Civil) - Escola de Engenharia, Universidade Estadual de Campinas, Campinas, 1997.

Zikmund, W. G. Business research methods. 5. ed. Fort Worth, TX: Dryden, 2000. 